\title{
Characterization of microRNA transcriptome in tumor, adjacent, and normal tissues of lung squamous cell carcinoma
}

\author{
Jun Wang, MD, PhD, ${ }^{\text {a }}$ Zhi Li, MD, PhD, ${ }^{\mathrm{a}}$ Qinyu Ge, PhD, ${ }^{\mathrm{b}}$ Weibing Wu, MD, ${ }^{\mathrm{a}}$ Quan Zhu, MD, ${ }^{\mathrm{a}}$ \\ Jinhua Luo, MD, and Liang Chen, $\mathrm{MD}^{\mathrm{a}}$
}

\begin{abstract}
Objectives: MicroRNAs are a class of regulatory molecules involved in a wide variety of biological processes, including growth, development, and apoptosis. Given the widespread roles of microRNAs in biological processes, understanding their different expression profiles in normal, adjacent, and tumor tissues will provide insights into the consequences of aberrant expression.
\end{abstract}

Methods: With the use of next-generation deep sequencing technology, microRNA profiles in 3 pooled samples from normal, adjacent, and tumor tissues of 19 patients with lung squamous cell carcinoma were characterized comprehensively. Quantitative polymerase chain reaction was used to verify the primary findings in another 38 lung squamous cell carcinoma tumor samples. In situ hybridization also was performed for validation.

Results: A total of 368, 306, and 231 known microRNAs were identified from tumor, adjacent, and normal pooled samples, respectively, of which 40, 44, and 26 microRNAs displayed dysregulation with 2-fold or greater change in 3 compared groups of tumor versus normal, tumor versus adjacent, and adjacent versus normal, respectively. Sequencing data also showed that some coexpressed microRNAs displayed a pattern of progressive dysregulation. Some of the microRNAs exhibited consistent changes; among them, miR-425-5p and miR-218-5p were confirmed by quantitative polymerase chain reaction and in situ hybridization, and proved that the microRNA expression levels were closely related to tumor stages and sizes. It is suggested that some microRNAs, such as miR-425 and miR-183, might be a driver for tumor formation, growth, and progression to higher staging, whereas others, such as miR-218, might behave as a tumor suppressor in lung cancer. Functional annotation analysis indicated that the proteoglycan pathway in cancer and mitogen-activated protein kinase, Wnt, PI3KAkt, and transforming growth factor-beta signaling pathways might be involved in the pathogenesis of lung squamous cell carcinoma.

Conclusions: This study describes the use of deep sequencing for comprehensive profiling of microRNAs in lung squamous cell carcinoma. The identified microRNA signatures may provide biomarkers for early detection, subclassification, and potential therapeutic targets of lung squamous cell carcinoma. This study also provides some insights into the molecular mechanism underlying the development and progression of lung squamous cell carcinoma, which may prove helpful for early diagnosis and treatment of the disease. (J Thorac Cardiovasc Surg 2015;149:1404-14)

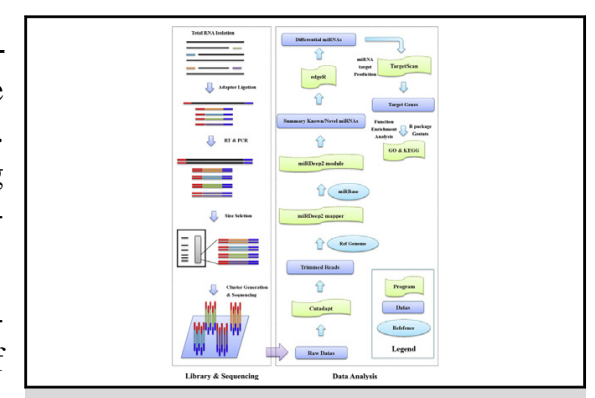

Flow chart of library preparation and data analysis of the lung cancer tissue miRNA profiling by deep sequencing.

\section{Central Message}

MicroRNA profiles and signatures of lung squamous cell cancer identified by next generation deep-sequencing method may provide potential biomarkers for early detection, subclassification, and potential therapeutic targets of lung SCC. These will provide some insight into the molecular mechanism underlying the development and progression of lung SCC.

\section{Perspective}

With the increasing incidence of lung cancer, it is clinically imperative to develop new biomarkers that can provide targets for diagnosis and treatment. We obtained miRNA profiles of lung SCC and found some coexpressed miRNAs with a pattern of progressive dysregulation. Further analysis first revealed that some miRNAs (eg, miR-425, miR-183, and miR-218) might be drivers for tumor formation, growth, and progression, or behave as a tumor suppressor with similar mechanisms reported in previous studies of other cancers. The current study can provide important basic data for studying the pathogenesis of lung cancer and has laid the foundation for recognizing candidate biomarkers.

See Editorial Commentary page 1415 .
From the Department of Thoracic and Cardiovascular Surgery, ${ }^{a}$ Jiangsu Province People's Hospital and the First Affiliated Hospital of Nanjing Medical University, Nanjing, People's Republic of China; and Key Laboratory of Child Development and Learning Science, ${ }^{\mathrm{b}}$ Ministry of Education, Southeast University, Nanjing, People's Republic of China.

This work was supported in part by Jiangsu Provincial Department of Education (Grants CXZZ11_0726), the Priority Academic Program of Jiangsu Higher Education Institutions (Grants JX10231801), and the projects 61271055 of the National Natural Science Foundation of China.
Received for publication Nov 24, 2014; revisions received Feb 3, 2015; accepted for publication Feb 7, 2015; available ahead of print March 23, 2015

Address for reprints: Liang Chen, MD, Department of Thoracic and Cardiovascular Surgery, Jiangsu Province People's Hospital and the First Affiliated Hospital of Nanjing Medical University, 300 Guangzhou Rd, Nanjing, Jiangsu 210029,

People's Republic of China (E-mail: njmuclbright@163.com). 0022-5223/\$36.00

Copyright (C) 2015 by The American Association for Thoracic Surgery http://dx.doi.org/10.1016/j.jtcvs.2015.02.012 


\section{Abbreviations and Acronyms \\ miRNA $=$ microRNA \\ NSCLC $=$ non-small-cell lung cancer \\ nt $=$ nucleotide \\ $\mathrm{qPCR}=$ quantitative polymerase chain reaction \\ qRT-PCR $=$ quantitative reverse transcription polymerase chain reaction \\ $\mathrm{SCC}=$ squamous cell carcinoma}

\section{Supplemental material is available online.}

Lung cancer is the leading cause of cancer-related mortality worldwide, accounting for $29 \%$ of cancer deaths in male patients and $26 \%$ of cancer deaths in female patients. ${ }^{1}$ Genome molecular assays recently have been used in the diagnosis of lung cancer. Despite recent advances in diagnosis and treatment strategies, the prognosis of lung cancer remains poor, with a 5 -year overall survival of $16 \%{ }^{2,3}$ The development of new therapeutic targets for early diagnosis and treatment may reduce the mortality of lung cancer. ${ }^{3}$ Furthermore, the ability to identify lung cancer with lymph node metastasis or recurrence after surgical resection would provide a case of guiding significance in adjuvant therapies, while sparing patients without metastasis from unnecessary cytotoxic chemotherapy and reducing the death rate. ${ }^{4}$

Non-small-cell lung cancer (NSCLC), the most common type of lung cancer, includes 2 major histologic subtypes: squamous cell carcinoma (SCC) and adenocarcinoma. ${ }^{5}$ Differentiation between SCC and adenocarcinoma has become an increasingly important issue in the management of lung cancer, because different treatments have diverse therapeutic or adverse effects depending on the histologic type. $^{6}$ Altogether, it is clinically imperative to develop new biomarkers that can improve early detection and subclassification, predict recurrence of NSCLC, and identify novel molecular targets for treatment.

MicroRNAs (miRNAs) are endogenous noncoding small RNAs of approximately 18 to 25 nucleotides (nt). ${ }^{7}$ Mature miRNAs are highly conserved RNA molecules that can regulate the expression of genes by hybridizing to complementary sequences in the $3^{\prime}$ untranslated region of target miRNAs. ${ }^{8}$ Many studies have demonstrated that miRNAs participate in various biological processes, including cell proliferation, differentiation, and apoptosis. ${ }^{9}$ In addition, studies have shown that miRNAs play roles in the development and progression of lung cancer by promoting the expression of oncogenes or by inhibiting tumor suppressor genes. ${ }^{10-14}$

Although quantitative reverse transcription polymerase chain reaction (qRT-PCR) and microarrays have been used to identify lung cancer-associated miRNA aberrations, ${ }^{15}$ these technologies only measure relative abundance of known miRNAs. Recent cancer profiling studies have focused on next-generation sequencing, ${ }^{16}$ knowing that high throughput sequencing of miRNAs can avoid the limitations of microarrays and allow for massive parallel sequencing of millions of sequences on chips, thus generating a greater number of transcript sequences even if finding many novel miRNAs that is impossible by microarray analysis. ${ }^{17}$

Illumina (Illumina Inc, San Diego, Calif) and SOLiD (Applied Biosystems, Waltham, Mass) have been used to profile serum miRNAs of patients with lung cancer. ${ }^{18,19}$ Several reports showed that miRNAs were differentially expressed in tumor tissues. However, there is no study reporting the use of next-generation deep sequencing for systematic characterization of miRNA transcriptome of tumor, adjacent, and normal tissues in patients with lung cancer. Deep sequencing-based miRNA profiling directly from clinically defined and histologically confirmed surgical tumor tissues is important because it is diseasespecific. Characterization of miRNA transcriptome in lung tumor, adjacent, and normal tissues by nextgeneration deep sequencing may help develop strategies to improve early diagnosis and treatment of NSCLC.

The aim of the present study was to systematically characterize alterations of miRNAs in surgically resected lung tumor and adjacent tissues by using next-generation sequencing in an attempt to (1) comprehensively profile the expression pattern of miRNAs in SCC; (2) verify the findings obtained from the pairwise pooled SCC samples in other tumor tissues using quantitative polymerase chain reaction (qPCR); and (3) evaluate whether miRNAs could provide potential diagnosis and therapeutic targets for SCC by functionally analyzing the roles of the differentially expressed miRNAs.

\section{MATERIAL AND METHODS}

\section{Sample Preparation and RNA Isolation}

We collected 19 groups of clinical samples. Every group included cancerous tissues, tumor-adjacent tissues, and normal control tissues of SCCs. We also collected another 38 cancerous tissues from SCC for qPCR validation. All samples mentioned were obtained from Jiangsu Province People's Hospital with informed consent from all patients concerned. This study was approved by the Ethics Committee of Jiangsu Province People's Hospital. miRNAs were isolated from approximately $50 \mathrm{mg}$ of tissue from each sample using a mirVana miRNA isolation Kit (Ambion, Austin, Tex), with some modifications according to the manufacturer's instructions. The quantity and quality of obtained miRNAs were measured with a Qubit 2.0 Fluorometer (Life Technologies, Grand Island, NY) according to the manufacturer's protocol.

\section{Deep Sequencing}

For high-throughput small RNAs sequencing, 3 pooled samples (SCC tumor, adjacent, and normal tissues) were prepared by equally mixing the 19 corresponding samples. Small RNA libraries were established for deep sequencing as described in previous reports ${ }^{17,20-24}$ according to the 
manufacturer's protocols. Briefly, sample RNAs were adapter-ligated using T4 RNA ligase and subsequently reverse-transcribed into cDNA by SuperScript II Reverse Transcriptase (Life Technologies). The cDNA fragments were polymerase chain reaction amplified for subsequent sequencing. Illumina HiSeq 2500 (Illumina Inc) was used for sequencing of the RNA libraries. The process of library preparation and sequencing data analysis is shown in Figure 1.

CAP-miRSeq was used for data analysis according to the user guider with some modifications. ${ }^{25}$ The mean length of Illumina sequence reads was $41 \mathrm{nt}$, greater than the mean size of miRNAs (19-25 nt). Because the reads contained part of the $3^{\prime}$-adaptor at the end of the sequences, we used Novoalign (V2.08.01 Novocraft 2010; www.novocraft.com) to cut all reads at the $3^{\prime}$-end to remove the adapter sequences. After adaptor trimming, reads less than 12 bases were discarded. Then, trimmed reads were input into miRDeep2 to quantify known miRNAs against miRBase and predict novel miRNAs (http://sourceforge.net/projects/mireap/). Expression values of miRNAs were selected for the differential expression analysis using tool edgeR from Bioconductor, as described previously ${ }^{26}$ (Figure 1). The screening criteria for differential miRNAs was defined as normalization reads greater than 50 , the absolute value of fold-change ( $\log 2$ [case/control]) was greater than 2 , and its $P$ value was less than .05 .

\section{Quantitative Validation of MicroRNAs by Quantitative Real-Time Polymerase Chain Reaction and In Situ Hybridization}

qRT-PCR was performed to validate the expression levels of miRNAs analyzed by sequencing according to the previous studies. ${ }^{18}$ Dissociation curve was performed in each reaction to verify the effectiveness. U6 small nuclear RNA was used as an internal reference control. The $\Delta \Delta \mathrm{Ct}$ method was used for data analysis. ${ }^{27}$

Detection of miRNAs by in situ hybridization with riboprobes was essentially as described by $\mathrm{Li}$ and colleagues ${ }^{28}$ and Silahtaroglu and colleagues. ${ }^{29}$ Briefly, the tissues were deparaffinized, dehydrated, and subsequently immersed in $0.2 \mathrm{~N} \mathrm{HCl}$, and the tissues were then fixed in $10 \%$ neutral-buffered formalin. After digestion with proteinase $\mathrm{K}$, the slides were then prehybridized at $37^{\circ} \mathrm{C}$ for 2 hours, followed by the hybridization with probe at $37^{\circ} \mathrm{C}$ for 24 hours. miR-425-5p and miR-218-5p were detected by in situ hybridization for validation in this study.

\section{Prediction and Enrichment Analysis of Target Genes}

Target genes of differentially expressed miRNAs were predicted using TargetScan software (http://www.targetscan.org/). ${ }^{30}$ Gene Ontology ${ }^{31}$ enrichment analysis of the target genes was performed to investigate the functional distribution of differentially expressed miRNAs from tumor, adjacent, and normal tissues. In addition, KEGG pathway analysis of the target genes was also performed as previously described. ${ }^{22,32}$

\section{RESULTS}

\section{Analysis of Sequenced Small RNAs}

A total of 3.3 million (tumor tissue), 3.1 million (adjacent tissue), and 2.2 million (normal tissue) raw reads were generated from the 3 libraries. As shown in Figure E1, reads with a length of $22 \mathrm{nt}$ were the most abundant, followed by 23 and 21 nt reads, which corresponded to the mean length of miRNAs. Small RNAs of 20 to $24 \mathrm{nt}$ in length accounted for $94.4 \%$ (tumor), $88.2 \%$ (adjacent), and $86.5 \%$ (normal) of the total number of small RNA reads. In this study, a total of 196 novel miRNA sequences were identified from RNA libraries, with 84, 63, and 49 novel miRNAs in tumor, adjacent, and normal pooled samples, respectively.

\section{Differential Expression Analysis of MicroRNAs in Tumor, Adjacent, and Normal Tissues of Lung Squamous Cell Carcinoma}

A total of 44 (25 upregulated and 19 downregulated), 40 (26 upregulated and 14 downregulated), and 26 (8 upregulated and 18 downregulated) known miRNAs were identified to be differentially expressed in tumor versus normal samples, adjacent versus normal samples, and tumor versus adjacent samples, respectively. As shown in Table E1 and Figure E2, hsa-miR-135a-5p was the most downregulated miRNA in the tumor tissue compared with the normal control, representing an approximately 4-fold change. In contrast, hsa-miR-205-5p and hsa-miR-31-5p were the most upregulated, representing an approximately 6-fold change. With stricter cutoff criteria (fold change $>3$ and $P<.05), 11$ miRNAs displayed considerable expression differences between the tumor and normal tissues (all $P<.001)$; 9 were upregulated and 2 were downregulated (Figure 2, A). Fourteen miRNAs exhibited substantial differences between the tumor and adjacent tissues; 10 were upregulated and 4 were downregulated (Figure 2, B). Only 6 miRNAs exhibited extremely differences between the adjacent and normal tissues; 2 were upregulated and 4 were downregulated (Figure 2, $C$ ). In addition, 5 miRNAs (hsa-miR-135a-5p, 205-5p, 31-5p, 196b-5p, and 1246) displayed altered expressions in both adjacent and normal tissues compared with the tumor tissue (Figure 2, A-C).

\section{MicroRNA Expression Shows Gradual Changes From Normal to Tumor Tissues of Squamous Cell Carcinoma}

In this study, we considered those miRNAs were gradually changed, which upregulated or downregulated significantly with fold-change greater than 2 and $P$ value less than .05 , from normal tissues to tumor tissues. We obtained 12 miRNAs as shown in Figure 3, $A$, of which 5 miRNAs (let-7a-3p, miR$140-5 p, 34 c-5 p, 218-5 p$, and 449a) were gradually downregulated, and 7 miRNAs (miR-409-3p, 424-5p, 19a-3p, 454-3p, $708-5 p, 425-5 p$, and $183-5 p$ ) were gradually upregulated. Among them, 2 of the gradually changed miRNAs (miR425-5p, miR-218-5p) were confirmed by qPCR (Figure 3, $B$ ).

\section{Quantitative Real-Time Polymerase Chain Reaction and In Situ Hybridization Validation of the Differential Expression of MicroRNAs}

To confirm the deep sequencing results, qRT-PCR was used to assess the expression of 10 miRNAs (mir-205-5p, 31-5p, 196b-5p, 425-5p, 337-5p, 183-5p, 135a-5p, 218-5p, 625-3p, and let-7a-3p) in the same samples of SCC as those used in deep sequencing (19 tumor tissues, 19 adjacent tissues, and 19 normal tissues). These 10 miRNAs were selected to represent highly expressed miRNAs and low expressed miRNAs, but all showed significant dysregulation among the pooled samples of lung SCC. Of them, 2 


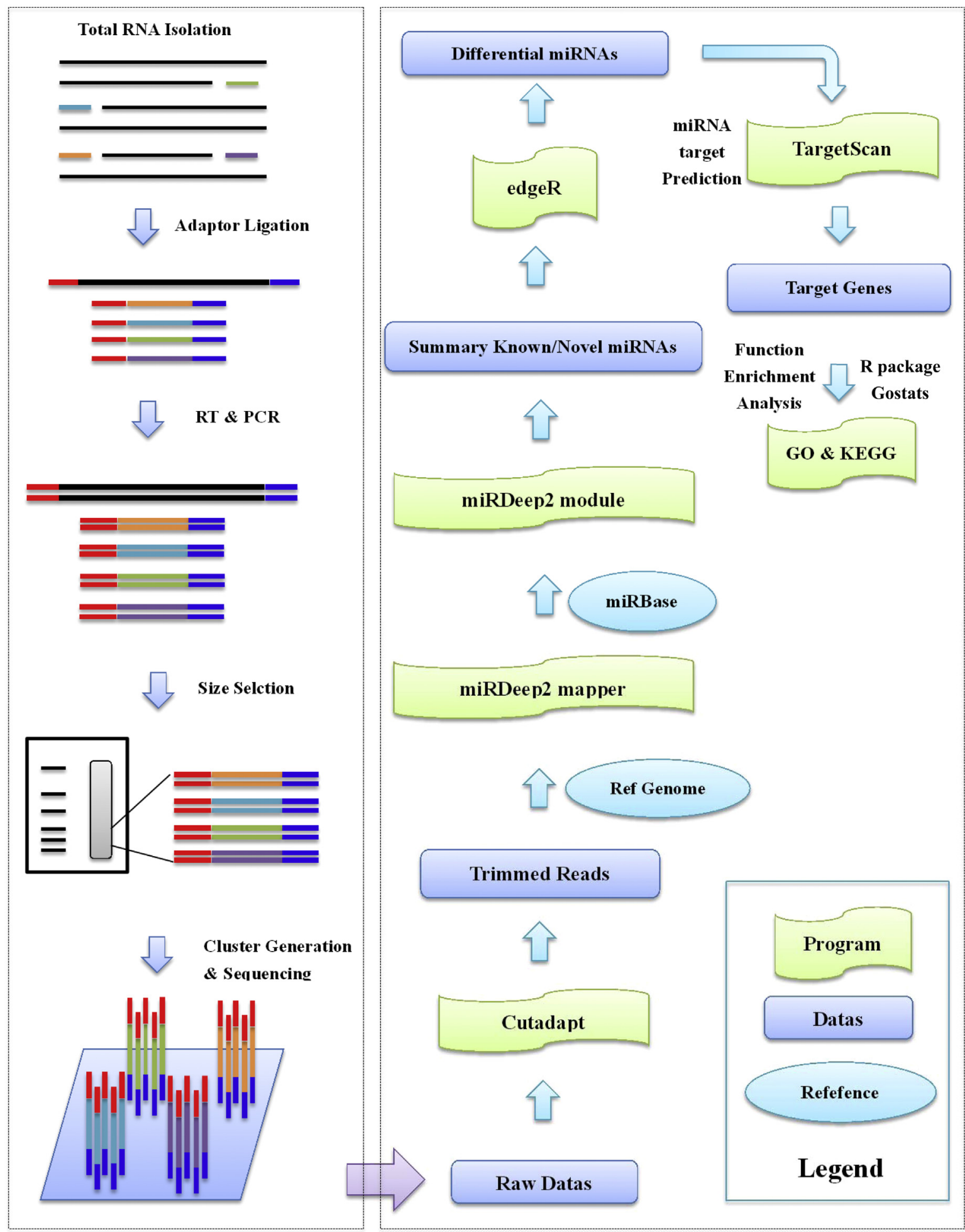

\section{Library \& Sequencing}

Data Analysis

FIGURE 1. Flow chart of library preparation and data analysis of the lung cancer tissue miRNA profiling by deep sequencing. GO, Gene Ontology; $m i R N A$, microRNA; $R T \& P C R$, reverse transcription polymerase chain reaction; $K E G G$, Kyoto Encyclopedia of Genes and Genomes. 

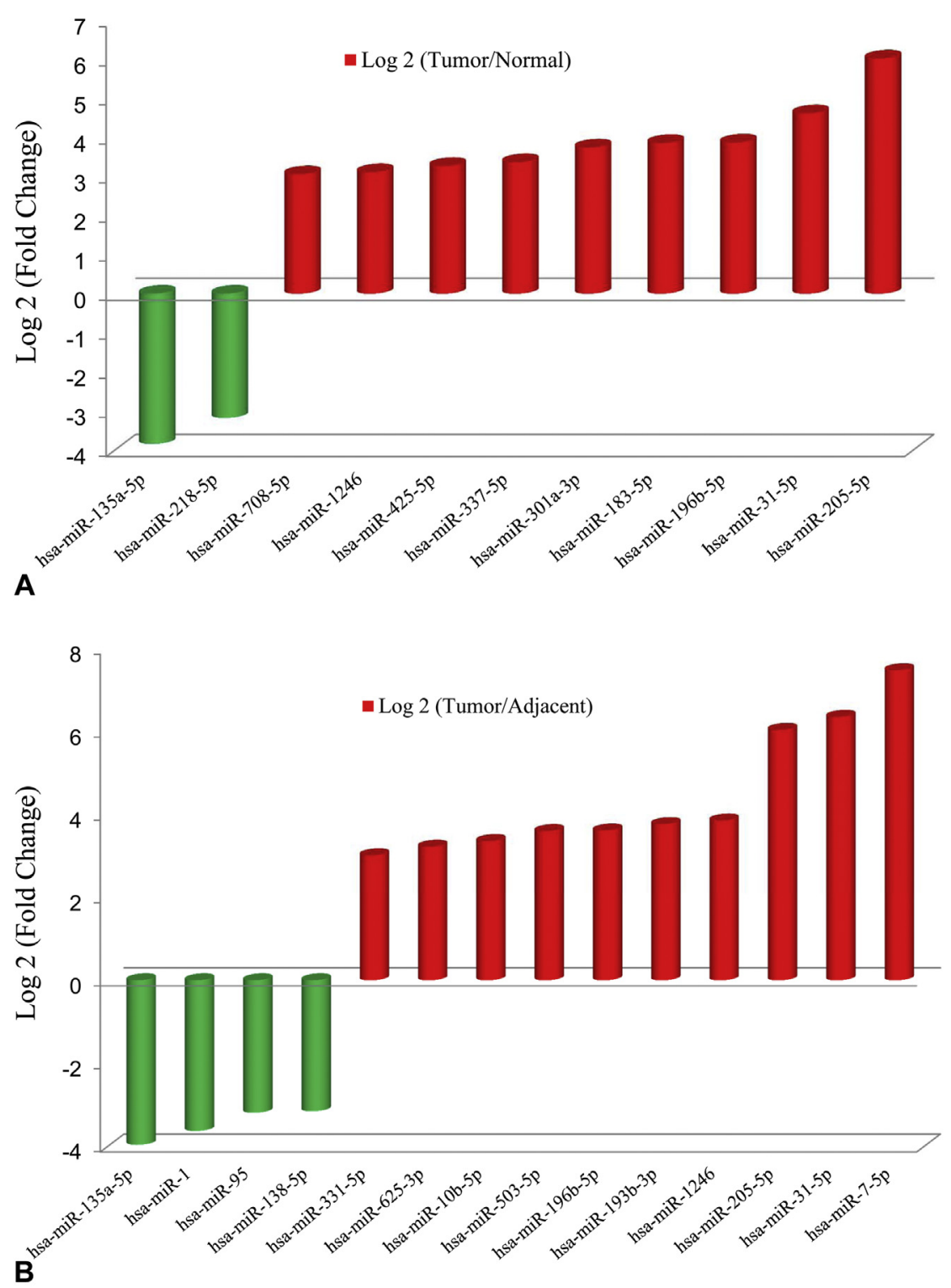

\section{C}

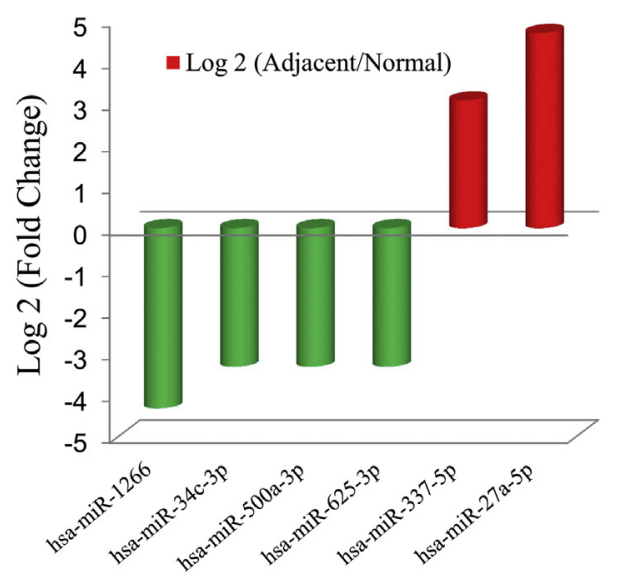

FIGURE 2. Significantly differentially expressed miRNAs in tumor, adjacent, and normal tissues. A, Upregulated and downregulated miRNAs in tumor versus normal tissues as defined by deep sequencing. B, Upregulated and downregulated miRNAs in tumor versus adjacent tissues as defined by deep sequencing. C, Upregulated and downregulated miRNAs in adjacent versus normal tissues as defined by deep sequencing. 

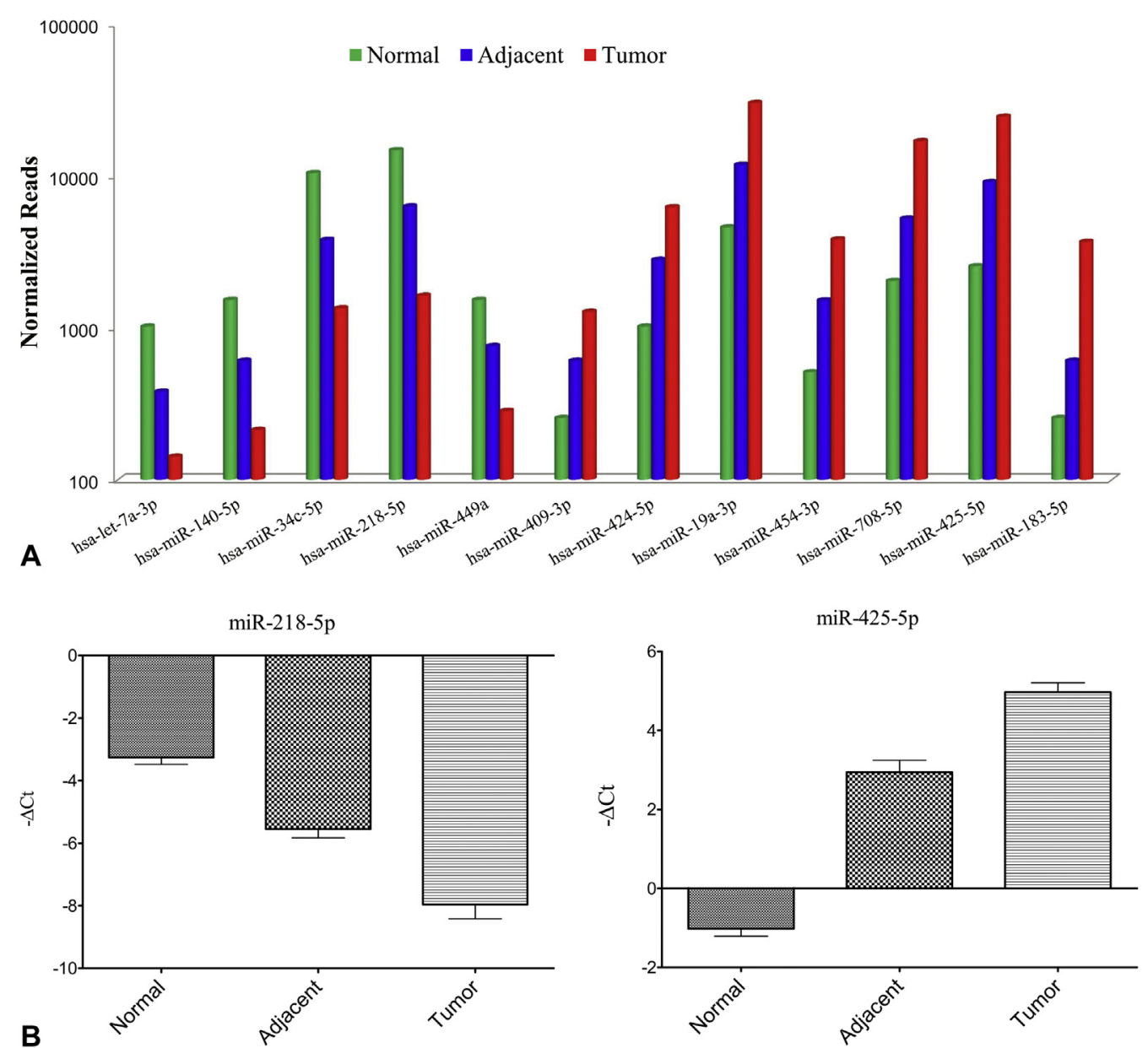

FIGURE 3. miRNA expression level shows a gradual significant change from normal tissue to tumor tissue. A, Some of them are upregulated successively, and others are downregulated successively. B, qPCR validation of the 2 related miRNAs shows gradual changes from normal tissue to tumor tissue. The expression level of miR-218-5p shows decreasing changes, and miR-425-5p shows increasing changes.

(mir-625-3p, let-7a-3p) had a Ct value greater than 35, suggesting that the 2 miRNAs were not reliably measured by qPCR and thus excluded from further analysis. The other 8 miRNAs exhibited significantly different levels in the SCC tumor tissue compared with the normal or adjacent tissue $(P<.05)$ (Table E2). In addition, all of these changes detected by qRT-PCR were in the same direction as those detected by deep sequencing analysis, although the magnitude of changes differed between the 2 methods. The validation results obtained from a large set of tissues using qPCR suggested that the differential miRNAs could be signatures of SCC. As shown in Figure 4, the gradually changed expression of miR-425 and miR-218 from normal to tumor tissue of lung SCC was also confirmed by miRNA in situ hybridization.

\section{Associations Between MicroRNA Expression and Histopathologic Parameters of Squamous Cell Carcinoma}

To further substantiate the findings, expressions of 5 miRNAs (miR-425-5p, 31-5p, 337-5p, 183-5p, and 218-
$5 p$ ) selected from the results (Table E2) were assessed using another different 38 tumor tissues of SCCs with different stages and different tumor sizes. In line with the expected findings, all 5 miRNAs showed dysregulation in different tumor tissues of different stages. As shown in Figure 5, 4 miRNAs (miR-425-5p, 183-5p, 337-5p, and 218-5p) displayed distinctive expression levels in the tumor tissues of different stages (Figure 5, A) $(P<.05)$, and 2 miRNAs (miR-183-5p and 425-5p) showed a close correlation with tumor size (Figure 5, $B)(P<.05)$. However, there was no significant correlation between changes in miRNAs and age, gender, and race of the patients with SCC (all $P>.05$ ).

\section{MicroRNA Target Prediction and Functional Annotation}

A total of 5949 target genes of all differentially expressed miRNAs were predicted. All enriched Gene Ontology terms and the count of genes annotated are presented in Figure 6, $A-C$. We found a significant over-representation of the cellular process, single-organism process, and metabolic 

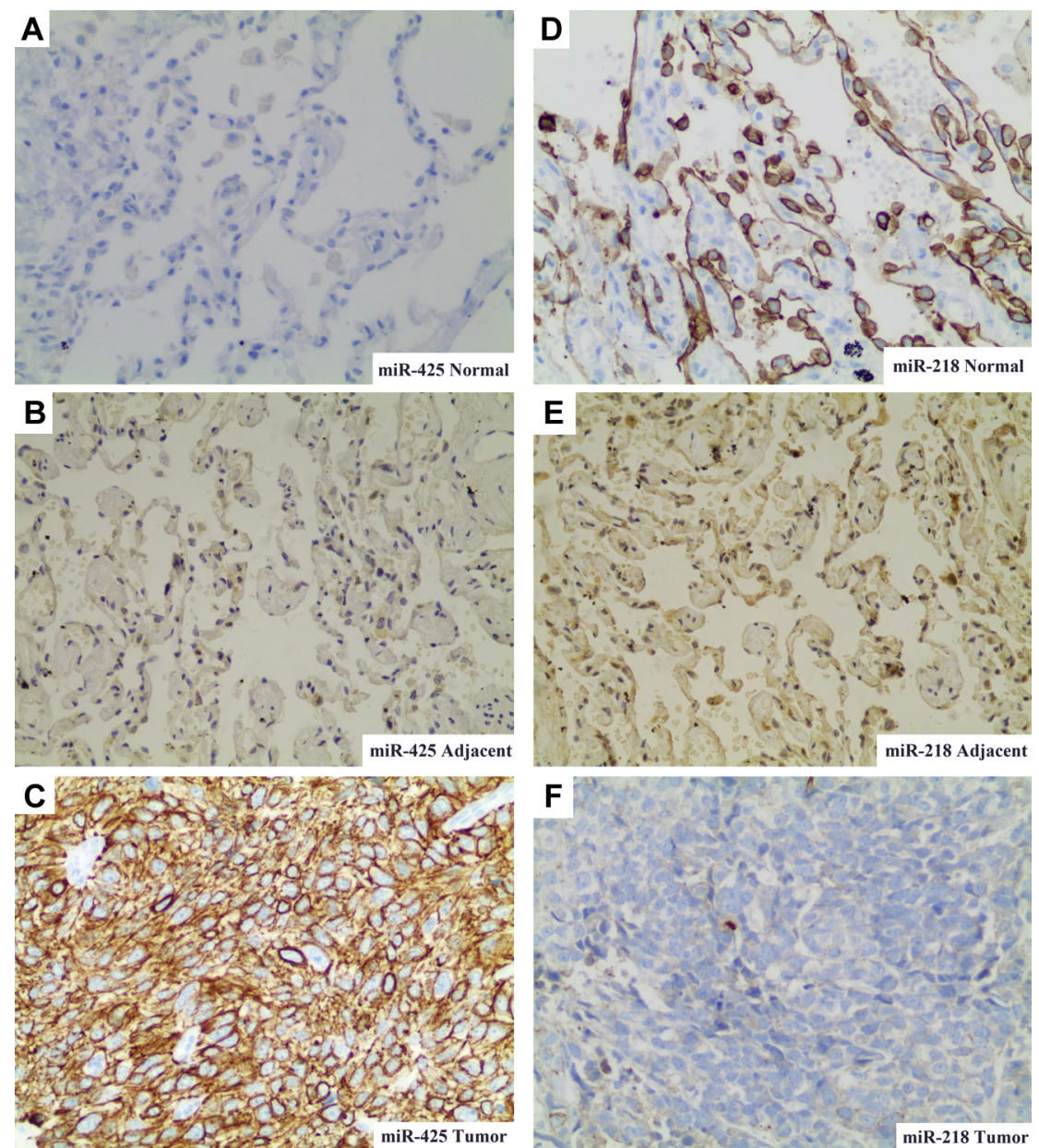

FIGURE 4. In situ hybridization assays for miR-425-5p and miR-218-5p were performed on tumor, adjacent, and normal lung tissues from patient with SCC. Representative results are shown. Gradually upregulated miR-425-5p (A-C) and gradually downregulated miR-218 (D-F) were detected in tumor, adjacent, and normal lung tissues.

processes for the biological process and binding, catalytic activity, and molecular transducer activity for the molecular function. As shown in Table 1, 20 significant pathways with a $P$ value less than .01 were identified. Of note, the top canonical pathways of differentially expressed miRNAs targets included pathways in cancer, endocytosis, protein processing in endoplasmic reticulum, proteoglycans in cancer, MAPK signaling pathway, and transforming growth factor-beta signaling pathway.

\section{DISCUSSION}

In this study, we defined differential expression of miRNAs in the tumor, adjacent, and normal tissues from patients with lung SCC by deep sequencing technology and found successive dysregulated miRNAs in those differential miRNAs coexpressed in the tumor, adjacent, and normal tissues. Some of these significantly differentially expressed miRNAs were confirmed by qRT-PCR, showing that the expression level of miR-425-5p, 183-5p, 337-5p, and 218-
$5 p$ increased or decreased in line with the stage and size of lung SCC tumors. These miRNAs were also defined as successive dysregulated miRNAs from normal to tumor tissues of lung SCC, implying that they might be acting as oncogene or tumor suppressor and associated with the development and progression of lung cancer. Further indepth study on the molecular mechanism underlying the development of lung SCC is warranted.

Among the differential miRNAs found in this study, many of them were already discovered and their functions were validated by the previous studies. ${ }^{12,33}$ The downregulated miRNAs in our study, such as let-7 family, has been verified to be inversely correlated to RAS protein expression $^{34}$ (Figure E2); the function of miR-126 that downregulated was also demonstrated to inhibit non-small cell lung cancer cell proliferation by targeting EGFL7 and SLC7A5 in the previous studies. ${ }^{35,36}$ On the contrary, the upregulated miRNAs in lung cancer were also detected in our study, such as miR-21, miR-221, and miR-17-92 

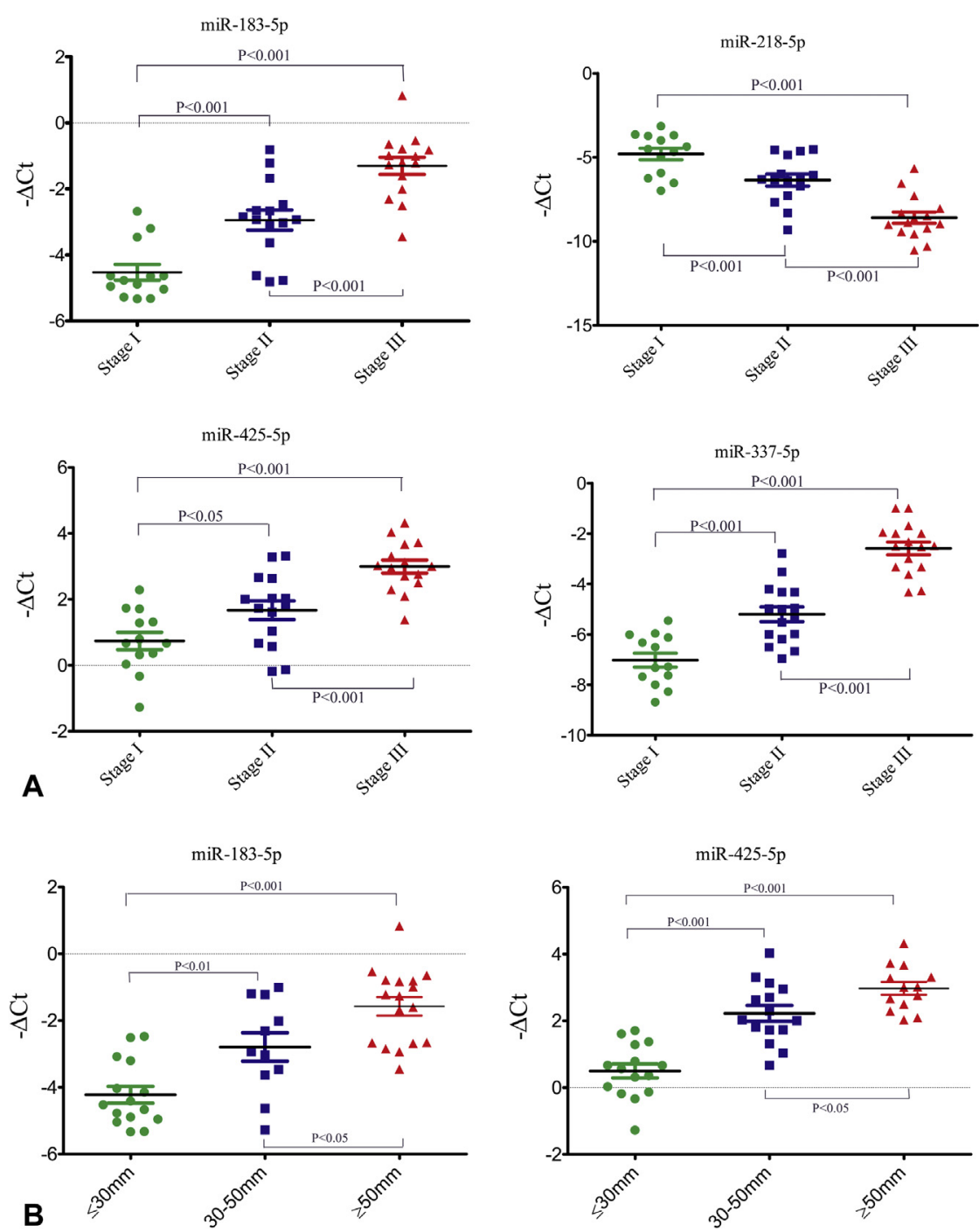

FIGURE 5. Associations between miRNA expression and different stages or tumor sizes of SCC. A, Expression levels of 4 miRNAs (miR-425-5p, 183-5p, 337-5p, and 218-5p) were significantly different and successively dysregulated from stage I to III of SCC as shown by qPCR. miR-218-5p showed downregulation, and other miRNAs showed upregulation. B, Expression levels of miR-183-5p and miR-425-5p increased with tumor size as shown by qPCR.

cluster, which has been defined as oncomir and denoted as epidermal growth factor receptor-regulated antiapoptotic factors in lung cancer. ${ }^{37-39}$ In this study, except those miRNAs that have been demonstrated to be related to lung cancer, some of the differential miRNAs were rarely reported in the previous studies of lung cancer, such as miR-425, which may be a driver for tumor formation, growth, and progression to higher staging in studies on gastric cancer and breast cancer, ${ }^{40,41}$ also upregulated successively from normal tissue to tumor tissues with further confirmation by qPCR and miRNA in situ hybridization, and the downregulated miR-218, which might be a tumor suppressor showing contrary tendency to miR-425, was also confirmed in our study ${ }^{42}$ (Figure 3, B, and Figure 4). All of these results imply the roles of these miRNAs in tumor genesis and development in a view of combining clinical process and biological explanation.

Our study also demonstrated that the miRNA signatures of SCC may be involved in pathways of cancer, particularly NSCLC. Of the predicted targets of these miRNAs, numerous vital genes are believed to participate in several important signaling pathways, including MAPK, transforming growth factor-beta, Wnt, Hippo, Neurotrophin, PI3KAkt, Insulin, and ErbB. Dysregulation of these miRNAs might function as oncogenes or tumor suppressors, thereby contributing to tumor initiation and progression. Modulation of miRNA expression holds great hope for potential cancer therapy. ${ }^{43,44}$ Therefore, our prediction that the differentially expressed miRNAs have the capability to target multiple components in these critical pathways makes them promising molecular targets for the treatment of SCC. 


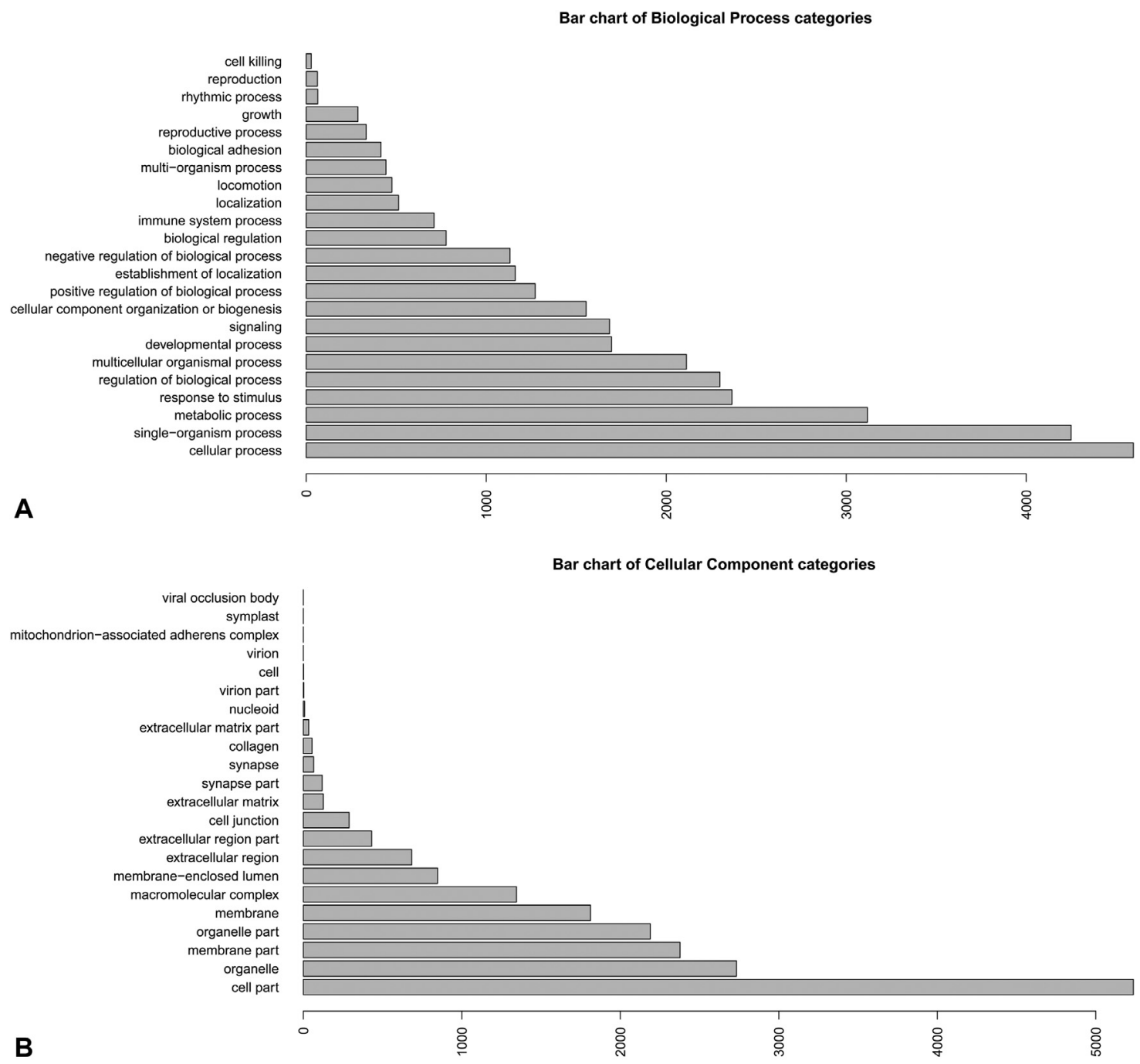

Bar chart of Molecular Function categories

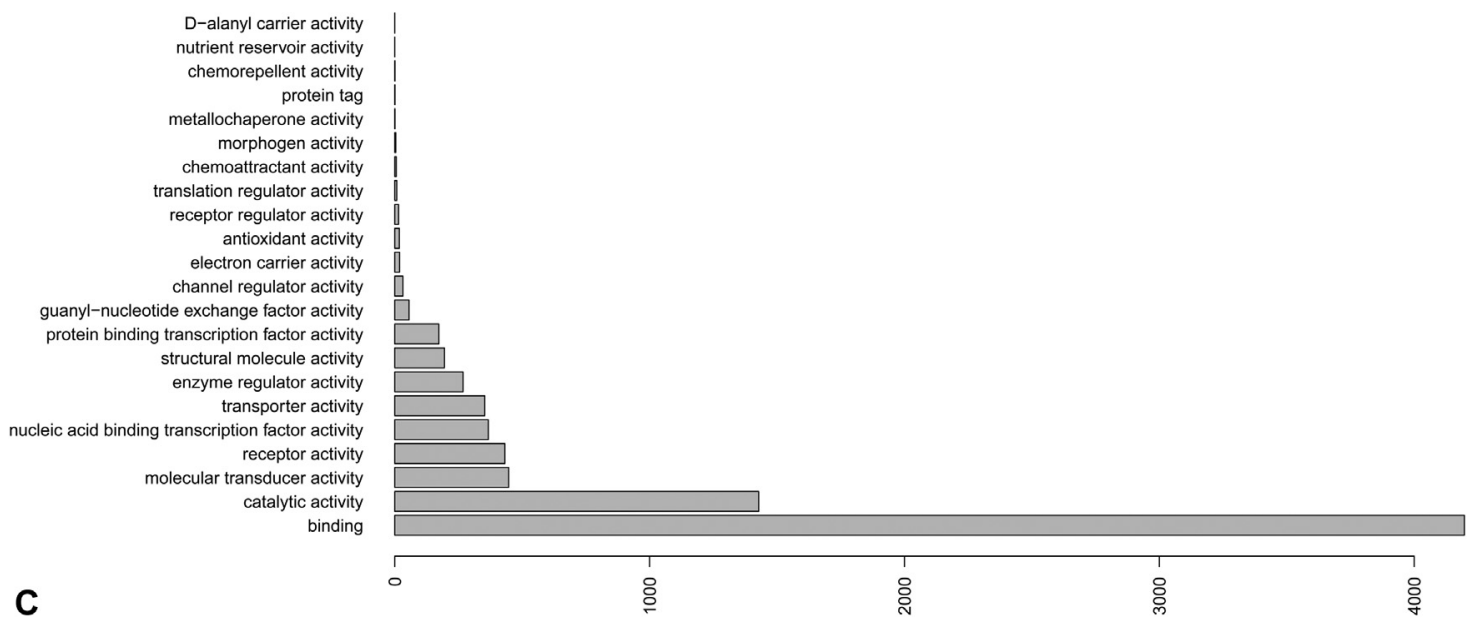

FIGURE 6. Categories and distribution of the Gene Ontology in terms of predicted miRNA targets. A, Biological process terms are enriched in cellular, metabolic, and single-organism processes. B, Cellular component terms are enriched in cell part, organelle, and membrane. C, Molecular function terms are enriched in binding, catalytic activity, and molecular transducer activity. 
TABLE 1. Enriched KEGG pathway, number of differentially expressed genes, and adjusted $P$ value and false discovery rate

\begin{tabular}{lccc}
\hline \multicolumn{1}{c}{ KEGG pathway } & Gene no. & Bonferroni $\boldsymbol{P}$ value & False discovery rate \\
\hline Pathways in cancer & 181 & $1.06 \mathrm{E}-18$ & $1.06 \mathrm{E}-18$ \\
Endocytosis & 122 & $2.57 \mathrm{E}-16$ & $1.29 \mathrm{E}-16$ \\
Protein processing in endoplasmic reticulum & 101 & $3.72 \mathrm{E}-14$ & $1.24 \mathrm{E}-14$ \\
Proteoglycans in cancer & 125 & $3.71 \mathrm{E}-13$ & $9.28 \mathrm{E}-14$ \\
MAPK signaling pathway & 135 & $2.68 \mathrm{E}-11$ & $5.35 \mathrm{E}-12$ \\
TGF-beta signaling pathway & 57 & $3.88 \mathrm{E}-11$ & $6.46 \mathrm{E}-12$ \\
Prostate cancer & 60 & $1.79 \mathrm{E}-10$ & $2.55 \mathrm{E}-11$ \\
Renal cell carcinoma & 48 & $4.54 \mathrm{E}-10$ & $5.68 \mathrm{E}-11$ \\
Wnt signaling pathway & 83 & $1.74 \mathrm{E}-09$ & $1.94 \mathrm{E}-10$ \\
Ubiquitin mediated proteolysis & 80 & $2.71 \mathrm{E}-09$ & $2.71 \mathrm{E}-10$ \\
Regulation of actin cytoskeleton & 112 & $3.03 \mathrm{E}-09$ & $2.76 \mathrm{E}-10$ \\
HTLV-I infection & 132 & $5.03 \mathrm{E}-09$ & $4.20 \mathrm{E}-10$ \\
Focal adhesion & 107 & $1.55 \mathrm{E}-08$ & $1.19 \mathrm{E}-09$ \\
Hippo signaling pathway & 85 & $3.60 \mathrm{E}-08$ & $2.57 \mathrm{E}-09$ \\
Neurotrophin signaling pathway & 69 & $6.42 \mathrm{E}-08$ & $4.28 \mathrm{E}-09$ \\
PI3K-Akt signaling pathway & 158 & $7.64 \mathrm{E}-08$ & $4.77 \mathrm{E}-09$ \\
Insulin signaling pathway & 76 & $1.55 \mathrm{E}-07$ & $9.10 \mathrm{E}-09$ \\
Axon guidance & 73 & $3.97 \mathrm{E}-07$ & $2.20 \mathrm{E}-08$ \\
ErbB signaling pathway & 53 & $1.01 \mathrm{E}-06$ & $5.05 \mathrm{E}-08$ \\
Small cell lung cancer & 52 & $2.04 \mathrm{E}-06$ & $9.73 \mathrm{E}-08$ \\
\hline
\end{tabular}

HTLV-1, Human T-cell lymphotropic virus; $T G F$, transforming growth factor; $K E G G$, Kyoto Encyclopedia of Genes and Genomes; $M A P K$, mitogen-activated protein kinases; ErbB, V-Erb-B2 avian erythroblastic leukemia viral oncogene homolog.

One of the advantages of the next-generation deep sequencing technology over conventional procedures is that it allows for the discovery of miRNAs that have not been related with malignancies by the traditional techniques. With the use of deep sequencing, we can identify a set of differentially expressed miRNAs whose dysregulation has not well been documented in lung tumorigenesis. Two of the 10 selected miRNAs that displayed dysregulations in SCC discovered by deep sequencing did not exhibit significant changes as assessed by qRT-PCR. The inconsistencies between the 2 approaches for assessing miRNA expression are not unusual, as demonstrated by previous studies of miRNAs using microarray, qRT-PCR, and highthroughput sequencing. . $^{2,45,46}$ One of the reasons underlying the observation might be that qRT-PCR has lower sensitivity than deep sequencing, and thus is not able to measure the difference of some miRNAs between normal and tumor tissues. In addition, the different proportions of the tumors in the specimens tested by deep sequencing than in the specimens assessed by qRT-PCR could lead to the inconsistent results between the 2 techniques.

\section{CONCLUSIONS}

This study described the use of deep sequencing for comprehensive profiling of miRNAs in tumor, adjacent, and normal tissues of lung SCC. Our comprehensive survey of differentially expressed miRNAs not only confirms some existing findings but also discovers dysregulated miRNAs that had not been found in lung carcinogenesis, thereby providing new signatures of SCCs. In addition, by using qRT-PCR and in situ hybridization, we validated miRNA signatures that could distinguish tumor tissues from normal tissues and identified a small panel of miRNAs that can differentiate different stages of SCC by expression levels. The identified miRNAs may provide promising biomarkers to improve early detection, subclassification, and monitoring of SCC in the future.

\section{Conflict of Interest Statement}

Authors have nothing to disclose with regard to commercial support.

The authors thank all the individuals who voluntarily participated in the study. Jun Wang and Zhi Li contributed equally to this work. The authors give special thanks to Qinyu Ge for aid in the experimental design; Weibing $\mathrm{Wu}$, Quan Zhu, and Jinhua Luo for aid in surgical specimen preparation; and Liang Chen for insightful suggestions on the manuscript modification.

\section{References}

1. Jemal A, Siegel R, Ward E, Hao Y, Xu J, Thun MJ. Cancer statistics, 2009. CA Cancer J Clin. 2009;59:225-49.

2. Alberg AJ, Ford JG, Samet JM. Epidemiology of lung cancer: ACCP evidencebased clinical practice guidelines (2nd edition). Chest. 2007;132:29S-55S.

3. Siegel R, Naishadham D, Jemal A. Cancer statistics, 2013. CA Cancer J Clin. 2013:63:11-30.

4. Winton T, Livingston R, Johnson D, Rigas J, Johnston M, Butts C, et al. Vinorelbine plus cisplatin vs. observation in resected non-small-cell lung cancer. $N$ Engl J Med. 2005;352:2589-97.

5. Travis WD, Brambilla E, Noguchi M, Nicholson AG, Geisinger KR, Yatabe Y, et al. International Association for the Study of Lung Cancer/American Thoracic Society/European Respiratory Society international multidisciplinary classification of lung adenocarcinoma. J Thorac Oncol. 2011;6:244-85. 
6. Mukhopadhyay S, Katzenstein AL. Subclassification of non-small cell lung carcinomas lacking morphologic differentiation on biopsy specimens: utility of an immunohistochemical panel containing TTF-1, napsin A, p63, and CK5/6. Am J Surg Pathol. 2011;35:15-25.

7. Bartel DP. MicroRNAs: genomics, biogenesis, mechanism, and function. Cell. 2004;116:281-97.

8. Valencia-Sanchez MA, Liu J, Hannon GJ, Parker R. Control of translation and mRNA degradation by miRNAs and siRNAs. Genes Dev. 2006;20:515-24.

9. Ambros V. MicroRNA pathways in flies and worms: growth, death, fat, stress, and timing. Cell. 2003;113:673-6.

10. Calin GA, Croce CM. MicroRNA signatures in human cancers. Nat Rev Cancer. 2006;6:857-66.

11. Nana-Sinkam SP, Croce CM. Non-coding RNAs in cancer initiation and progression and as novel biomarkers. Mol Oncol. 2011;5:483-91.

12. Kumar MS, Erkeland SJ, Pester RE, Chen CY, Ebert MS, Sharp PA, et al. Suppression of non-small cell lung tumor development by the let-7 microRNA family. Proc Natl Acad Sci U S A. 2008;105:3903-8.

13. Osada H, Takahashi T. let-7 and miR-17-92: small-sized major players in lung cancer development. Cancer Sci. 2011;102:9-17.

14. Fabbri M, Garzon R, Cimmino A, Liu Z, Zanesi N, Callegari E, et al. MicroRNA29 family reverts aberrant methylation in lung cancer by targeting DNA methyltransferases 3A and 3B. Proc Natl Acad Sci U S A. 2007;104:15805-10.

15. Shen J, Jiang F. Applications of microRNAs in the diagnosis and prognosis of lung cancer. Expert Opin Med Diagn. 2012;6:197-207.

16. Stratton MR, Campbell PJ, Futreal PA. The cancer genome. Nature. 2009;458: 719-24.

17. Oshlack A, Robinson MD, Young MD. From RNA-seq reads to differential expression results. Genome Biol. 2010;11:220.

18. Hu Z, Chen X, Zhao Y, Tian T, Jin G, Shu Y, et al. Serum microRNA signatures identified in a genome-wide serum microRNA expression profiling predict survival of non-small-cell lung cancer. J Clin Oncol. 2010;28:1721-6.

19. Keller A, Backes C, Leidinger P, Kefer N, Boisguerin V, Barbacioru C, et al. Next-generation sequencing identifies novel microRNAs in peripheral blood of lung cancer patients. Molecular Biosyst. 2011;7:3187-99.

20. Hamfjord J, Stangeland AM, Hughes T, Skrede ML, Tveit KM, Ikdahl T, et al. Differential expression of miRNAs in colorectal cancer: comparison of paired tumor tissue and adjacent normal mucosa using high-throughput sequencing. PloS One. 2012;7:e34150.

21. Jima DD, Zhang J, Jacobs C, Richards KL, Dunphy CH, Choi WW, et al. Deep sequencing of the small RNA transcriptome of normal and malignant human B cells identifies hundreds of novel microRNAs. Blood. 2010;116:e118-27.

22. Kozubek J, Ma Z, Fleming E, Duggan T, Wu R, Shin DG, et al. In-depth characterization of microRNA transcriptome in melanoma. PloS One. 2013;8:e72699.

23. Osanto S, Qin Y, Buermans HP, Berkers J, Lerut E, Goeman JJ, et al. Genomewide microRNA expression analysis of clear cell renal cell carcinoma by next generation deep sequencing. PloS One. 2012;7:e38298.

24. Rohr C, Kerick M, Fischer A, Kuhn A, Kashofer K, Timmermann B, et al. Highthroughput miRNA and mRNA sequencing of paired colorectal normal, tumor and metastasis tissues and bioinformatic modeling of miRNA-1 therapeutic applications. PloS One. 2013;8:e67461.

25. Sun Z, Evans J, Bhagwate A, Middha S, Bockol M, Yan H, et al. CAP-miRSeq: a comprehensive analysis pipeline for microRNA sequencing data. BMC Genomics. 2014;15:423.

26. Friedlander MR, Chen W, Adamidi C, Maaskola J, Einspanier R, Knespel S, et al. Discovering microRNAs from deep sequencing data using miRDeep. Nat Biotechnol. 2008;26:407-15.

27. Livak KJ, Schmittgen TD. Analysis of relative gene expression data using realtime quantitative PCR and the 2(-Delta Delta C(T)) Method. Methods. 2001; 25:402-8.
28. Li J, Li X, Li Y, Yang H, Wang L, Qin Y, et al. Cell-specific detection of miR-375 downregulation for predicting the prognosis of esophageal squamous cell carcinoma by miRNA in situ hybridization. PLoS One. 2013;8:e53582.

29. Silahtaroglu AN, Nolting D, Dyrskjot L, Berezikov E, Moller M, Tommerup N, et al. Detection of microRNAs in frozen tissue sections by fluorescence in situ hybridization using locked nucleic acid probes and tyramide signal amplification. Nat Protoc. 2007;2:2520-8.

30. Lewis BP, Burge CB, Bartel DP. Conserved seed pairing, often flanked by adenosines, indicates that thousands of human genes are microRNA targets. Cell. 2005;120:15-20.

31. The Gene Ontology: enhancements for 2011. Nucleic Acids Res. 2012;40: D559-64.

32. Lang MF, Yang S, Zhao C, Sun G, Murai K, Wu X, et al. Genome-wide profiling identified a set of miRNAs that are differentially expressed in glioblastoma stem cells and normal neural stem cells. PloS One. 2012;7:e36248.

33. Takamizawa J, Konishi H, Yanagisawa K, Tomida S, Osada H, Endoh H, et al. Reduced expression of the let-7 microRNAs in human lung cancers in association with shortened postoperative survival. Cancer Res. 2004;64:3753-6.

34. Eder M, Scherr M. MicroRNA and lung cancer. N Engl J Med. 2005;352:2446-8.

35. Sun Y, Bai Y, Zhang F, Wang Y, Guo Y, Guo L. miR-126 inhibits non-small cell lung cancer cells proliferation by targeting EGFL7. Biochem Biophys Res Commun. 2010;391:1483-9.

36. Miko E, Margitai Z, Czimmerer Z, Varkonyi I, Dezso B, Lanyi A, et al. miR-126 inhibits proliferation of small cell lung cancer cells by targeting SLC7A5. FEBS Lett. 2011;585:1191-6.

37. Lu Y, Thomson JM, Wong HY, Hammond SM, Hogan BL. Transgenic overexpression of the microRNA miR-17-92 cluster promotes proliferation and inhibits differentiation of lung epithelial progenitor cells. Dev Biol. 2007;310:442-53.

38. Seike M, Goto A, Okano T, Bowman ED, Schetter AJ, Horikawa I, et al. MiR-21 is an EGFR-regulated anti-apoptotic factor in lung cancer in never-smokers. Proc Natl Acad Sci U S A. 2009;106:12085-90.

39. Markou A, Tsaroucha EG, Kaklamanis L, Fotinou M, Georgoulias V, Lianidou ES. Prognostic value of mature microRNA-21 and microRNA-205 overexpression in non-small cell lung cancer by quantitative real-time RTPCR. Clin Chem. 2008;54:1696-704.

40. Peng WZ, Ma R, Wang F, Yu J, Liu ZB. Role of miR-191/425 cluster in tumorigenesis and diagnosis of gastric cancer. Int J Mol Sci. 2014;15:4031-48.

41. Di Leva G, Piovan C, Gasparini P, Ngankeu A, Taccioli C, Briskin D, et al. Estrogen mediated-activation of miR-191/425 cluster modulates tumorigenicity of breast cancer cells depending on estrogen receptor status. PLoS Genet. 2013;9:e1003311.

42. Uesugi A, Kozaki K, Tsuruta T, Furuta M, Morita K, Imoto I, et al. The tumor suppressive microRNA miR-218 targets the mTOR component Rictor and inhibits AKT phosphorylation in oral cancer. Cancer Res. 2011;71:5765-78.

43. Lu J, Getz G, Miska EA, Alvarez-Saavedra E, Lamb J, Peck D, et al. MicroRNA expression profiles classify human cancers. Nature. 2005;435:834-8.

44. Tili E, Michaille JJ, Gandhi V, Plunkett W, Sampath D, Calin GA. miRNAs and their potential for use against cancer and other diseases. Future Oncol. 2007;3: 521-37.

45. Pradervand S, Weber J, Lemoine F, Consales F, Paillusson A, Dupasquier M, et al. Concordance among digital gene expression, microarrays, and qPCR when measuring differential expression of microRNAs. Biotechniques. 2010; 48:219-22.

46. Schee K, Lorenz S, Worren MM, Gunther CC, Holden M, Hovig E, et al. Deep Sequencing the MicroRNA Transcriptome in Colorectal Cancer. PLoS One. 2013;8:e66165.

Key Words: lung squamous cell carcinoma, microRNA, sequencing 


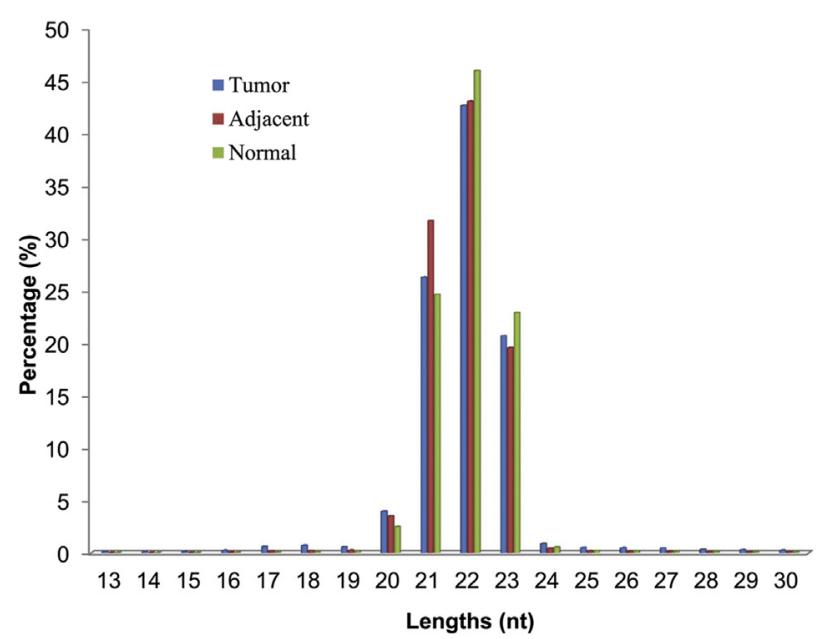

FIGURE E1. Length distribution and abundance of the small RNAs from ST, SA, and SN samples. Small RNA reads with a length of $22 \mathrm{nt}$ were the most abundant, which accounted for approximately half of the total reads, followed by 21 and $21 \mathrm{nt}$ reads. 


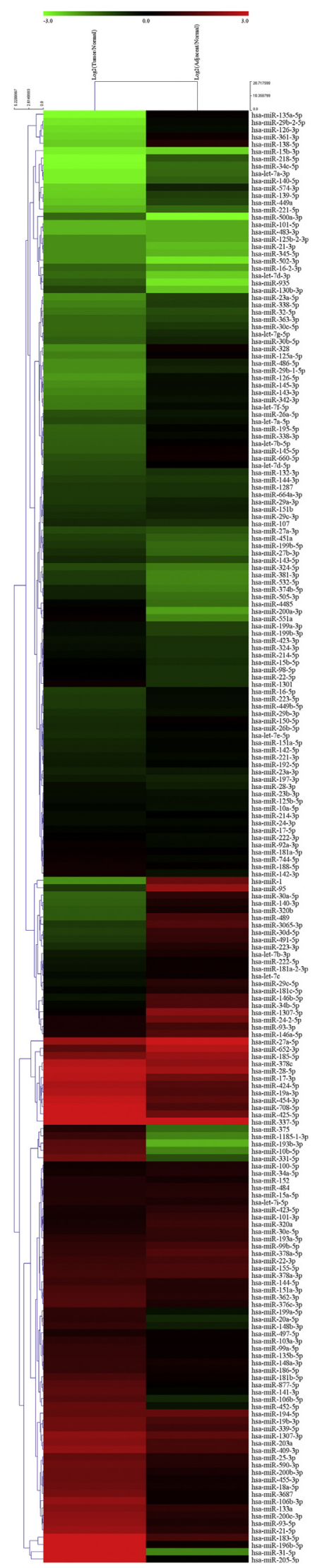

FIGURE E2. Hierarchical clustering analysis of miRNA expression in different tissues of lung SCC. Differential expression of miRNA in tumor and adjacent tissue compared with the normal tissue control. The data removed those low copy number miRNAs $(<10)$. The column shows each group to the control, and the line shows the fold change of each miRNA in lung cancer tissue. The color of each pattern represents the fold change as $\log 2$, from high (red) to low (green). 
TABLE E1. Upregulated and downregulated microRNAs among tumor, adjacent, and normal tissues as defined by deep sequencing

\begin{tabular}{|c|c|c|c|c|c|}
\hline miRNAs & Log2(tumor/normal) & miRNAs & $\log 2(\operatorname{adjacent} /$ normal $)$ & miRNAs & Log2(tumor/adjacent) \\
\hline hsa-miR-135a-5p & -3.85 & hsa-miR-1266 & -4.33 & hsa-miR-135a-5p & -3.96 \\
\hline hsa-miR-218-5p & -3.18 & hsa-miR-34c-3p & -3.33 & hsa-miR-1 & -3.62 \\
\hline hsa-miR-34c-5p & -2.96 & hsa-miR-500a-3p & -3.33 & hsa-miR-95 & -3.19 \\
\hline hsa-let-7a-3p & -2.85 & hsa-miR-625-3p & -3.33 & hsa-miR-138-5p & -3.15 \\
\hline hsa-miR-15b-3p & -2.85 & hsa-miR-502-3p & -2.75 & hsa-miR-361-3p & -2.84 \\
\hline hsa-miR-140-5p & -2.85 & hsa-miR-7-5p & -2.75 & hsa-miR-29b-2-5p & -2.69 \\
\hline hsa-miR-654-5p & -2.85 & hsa-miR-935 & -2.75 & hsa-miR-489 & -2.52 \\
\hline hsa-miR-760 & -2.85 & hsa-miR-15b-3p & -2.58 & hsa-miR-126-3p & -2.50 \\
\hline hsa-miR-29b-2-5p & -2.77 & hsa-let-7d-3p & -2.51 & hsa-miR-27a-5p & -2.28 \\
\hline hsa-miR-126-3p & -2.65 & hsa-miR-130b-3p & -2.43 & hsa-miR-3065-3p & -2.27 \\
\hline hsa-miR-361-3p & -2.58 & hsa-miR-21-3p & -2.33 & hsa-miR-30a-5p & -2.26 \\
\hline hsa-miR-574-3p & -2.54 & hsa-miR-345-5p & -2.26 & hsa-miR-328 & -2.10 \\
\hline hsa-miR-139-5p & -2.52 & hsa-miR-193b-3p & -2.23 & hsa-miR-1307-5p & -2.09 \\
\hline hsa-miR-138-5p & -2.50 & hsa-miR-101-5p & -2.16 & hsa-miR-574-3p & -2.01 \\
\hline hsa-miR-625-5p & -2.43 & hsa-miR-125b-2-3p & -2.16 & hsa-miR-106b-5p & 2.05 \\
\hline hsa-miR-449a & -2.43 & hsa-miR-483-3p & -2.16 & hsa-miR-200a-3p & 2.07 \\
\hline hsa-miR-101-5p & -2.26 & hsa-miR-16-2-3p & -2.06 & hsa-miR-106b-3p & 2.07 \\
\hline hsa-miR-221-5p & -2.26 & hsa-miR-200a-3p & -2.03 & hsa-miR-378d & 2.07 \\
\hline hsa-miR-4766-3p & -2.26 & hsa-miR-1307-5p & 2.19 & hsa-miR-210 & 2.12 \\
\hline hsa-miR-185-5p & 2.05 & hsa-miR-378c & 2.25 & hsa-miR-375 & 2.17 \\
\hline hsa-miR-133a & 2.15 & hsa-miR-95 & 2.34 & hsa-miR-339-3p & 2.22 \\
\hline hsa-miR-203a & 2.16 & hsa-miR-185-5p & 2.43 & hsa-miR-193a-3p & 2.31 \\
\hline hsa-miR-1307-3p & 2.24 & hsa-miR-28-5p & 2.50 & hsa-miR-335-3p & 2.48 \\
\hline hsa-miR-200c-3p & 2.27 & hsa-miR-652-3p & 2.74 & hsa-miR-183-5p & 2.60 \\
\hline hsa-miR-93-5p & 2.32 & hsa-miR-337-5p & 3.06 & hsa-miR-136-5p & 2.71 \\
\hline hsa-miR-106b-3p & 2.32 & hsa-miR-27a-5p & 4.68 & hsa-miR-361-5p & 2.71 \\
\hline hsa-miR-409-3p & 2.32 & & & hsa-miR-224-5p & 2.71 \\
\hline hsa-miR-27a-5p & 2.40 & & & hsa-miR-1180 & 2.81 \\
\hline hsa-miR-21-5p & 2.44 & & & hsa-miR-182-5p & 2.82 \\
\hline hsa-miR-424-5p & 2.61 & & & hsa-miR-200b-5p & 2.90 \\
\hline hsa-miR-19a-3p & 2.72 & & & hsa-miR-331-5p & 3.01 \\
\hline hsa-miR-378c & 2.74 & & & hsa-miR-625-3p & 3.22 \\
\hline hsa-miR-17-3p & 2.80 & & & hsa-miR-10b-5p & 3.36 \\
\hline hsa-miR-28-5p & 2.85 & & & hsa-miR-503-5p & 3.60 \\
\hline hsa-miR-454-3p & 2.91 & & & hsa-miR-196b-5p & 3.61 \\
\hline hsa-miR-708-5p & 3.05 & & & hsa-miR-193b-3p & 3.77 \\
\hline hsa-miR-1246 & 3.11 & & & hsa-miR-1246 & 3.85 \\
\hline hsa-miR-425-5p & 3.26 & & & hsa-miR-205-5p & 6.04 \\
\hline hsa-miR-337-5p & 3.36 & & & hsa-miR-31-5p & 6.36 \\
\hline hsa-miR-301a-3p & 3.74 & & & hsa-miR-7-5p & 7.48 \\
\hline hsa-miR-183-5p & 3.85 & & & & \\
\hline hsa-miR-196b-5p & 3.87 & & & & \\
\hline hsa-miR-31-5p & 4.61 & & & & \\
\hline hsa-miR-205-5p & 6.01 & & & & \\
\hline
\end{tabular}

miRNA, MicroRNA. 
TABLE E2. Expression levels of 8 microRNAs in 19 groups of tumor, adjacent, and normal tissues of squamous cell carcinoma as determined by quantitative reverse transcription polymerase chain reaction

\begin{tabular}{lcccccc}
\multicolumn{1}{c}{ miRNAs } & $\begin{array}{c}\text { Mean } \pm \text { SD in } \\
\text { tumor tissues }\end{array}$ & $\begin{array}{c}\text { Mean } \pm \text { SD in } \\
\text { adjacent tissues }\end{array}$ & $\begin{array}{c}\text { Mean } \pm \text { SD in } \\
\text { normal tissues }\end{array}$ & $\begin{array}{c}\boldsymbol{P} \text { value } \\
\text { (tumor vs normal) }\end{array}$ & $\begin{array}{c}\boldsymbol{P} \text { value } \\
\text { (tumor vs adjacent) }\end{array}$ & $\begin{array}{c}\boldsymbol{P} \text { value } \\
\text { (adjacent vs normal) }\end{array}$ \\
\hline miR-205-5p & $-5.35 \pm 0.23$ & $1.95 \pm 0.03$ & $2.02 \pm 0.13$ & $<.001$ & $<.001$ & $<.05$ \\
miR-31-5p & $-4.61 \pm 0.13$ & $3.84 \pm 0.19$ & $1.45 \pm 0.05$ & $<.001$ & $<.001$ & $<.001$ \\
miR-196b-5p & $0.35 \pm 0.09$ & $4.21 \pm 0.25$ & $4.28 \pm 0.08$ & $<.001$ & $<.001$ & $<.001$ \\
miR-425-5p & $-1.64 \pm 0.09$ & $0.42 \pm 0.10$ & $1.85 \pm 0.08$ & $<.001$ & $<.001$ & $<.001$ \\
miR-337-5p & $1.87 \pm 0.10$ & $2.22 \pm 0.11$ & $4.86 \pm 0.25$ & $<.001$ & $<.001$ & $<.001$ \\
miR-183-5p & $0.27 \pm 0.02$ & $3.11 \pm 0.20$ & $5.23 \pm 0.19$ & $<.001$ & $<.001$ & $<.001$ \\
miR-135a-5p & $4.44 \pm 0.20$ & $0.86 \pm 0.04$ & $0.91 \pm 0.04$ & $<.001$ & $<.001$ & $<.001$ \\
miR-218-5p & $4.36 \pm 0.09$ & $0.23 \pm 0.10$ & $-0.88 \pm 0.01$ & & & $<$ \\
\hline
\end{tabular}

miRNA, MicroRNA; $S D$, standard deviation. 